\title{
Chemotactic response of fish macrophages to Legionella pneumophila: correlation with pathogenicity
}

\author{
B. A. Weeks ${ }^{1}$, S. R. Sommer ${ }^{2}$, H. P. Dalton ${ }^{2}$ \\ ${ }^{1}$ Virginia Institute of Marine Science, School of Marine Science, College of William and Mary, Gloucester Point, Virginia \\ 23062, USA \\ ${ }^{2}$ Department of Pathology, Medical College of Virginia, Virginia Commonwealth University, Richmond, Virginia 23298, USA
}

\begin{abstract}
Chemotaxis is the directional migration of cells in response to a chemical stimulus. This phenomenon appears to be responsible for the accumulation of macrophages during inflammation. This work represents an attempt to understand certain aspects of host-parasite relationships in Legionnaire's Disease. In the first phase of this study, we measured the chemotactic stimulation of fish macrophages by 2 strains of Legionella pneumophila, one virulent and one avirulent for guinea pigs. Results from this part of the study, coupled with the possibility that reduced chemotaxis may be a factor contributing to increased virulence, led us to initiate the second phase of this work to determine the correlation between in vitro chemotaxis and the degree of virulence of $L$. preumophila for spot Leiostomus xanthurus. These studies demonstrated that virulent cells did not attract macrophages to the extent that avirulent cells did. The percentage of macrophages migrating toward virulent Legionella at 90 min was 24 as compared to 61 for the avirulent strain. In vivo studies showed that intraperitoneal injection of 1 to $2 \times 10^{10}$ viable cells of virulent $L$. pneumophila killed $100 \%$ of the fish within $2 \mathrm{~d}$ whereas the same number of avirulent $L$. pneumophila resulted in death in only $58 \%$ of the fish within $2 \mathrm{~d}$ after injection.
\end{abstract}

\section{INTRODUCTION}

In higher vertebrates, inflammation is a response of the cellular immune system to microbial invasion and/ or tissue injury Macrophages, which are important components of the cellular immune system, are believed to accumulate at the site of inflammation in response to chemical stimulants generated at the site. The factors stimulating this migration may be of microbial or host origin. This directional movement of phagocytic cells along chemical gradients is termed chemotaxis. Chemotactic movement has been investigated in mammals, primarily in rodents and man (Wilkinson 1974, Snyderman \& Goetzl 1981), but this important part of the immune system has not been studied extensively in lower vertebrates. Ellis (1977) reviewed the literature on early attempts to demonstrate chemotaxis in fish. Several recent reports have described the in vitro chemotactic activities of macrophages and neutrophils from various fish species (Griffin 1984, Obenauf \& Smith 1985, Weeks et al. 1986). This laboratory has recentiy investigated another macrophage function, phagocytosis, with mac- rophages from spot Leiostomus xanthurus and hogchoker Trinectes maculatus (Weeks \& Warinner 1984).

The stimulatory effect of Legionella pneumophila on macrophage chemotaxis in fish has not been investigated. This microorganism is responsible for Legionnaire's Disease in man and is present in both freshwater and estuarine environments (Fliermans et al. 1981). The present study was undertaken to determine whether Leiostomus xanthurus macrophages show a directional migratory response in vitro to $L$. pneumophila and to compare 2 strains of L. pneumophila, one virulent and one avirulent in mammals, for their ability to elicit chemotactic movement of fish macrophages. Intraperitoneal injection of these 2 strains into $L$. xanthurus resulted in more rapid death following inoculation of the virulent strain. We suggest that reduced chemotaxis may contribute to the virulence of $L$. pneumophila.

\section{MATERIALS AND METHODS}

Fish. Leiostomus xanthurus (average weight $23 \mathrm{~g}$; average length $119 \mathrm{~mm}$ ) employed in this study were 
captured by trawl net from the Ware and Nansemond Rivers (Chesapeake Bay tributaries) on several occasions from May 1984 through October 1985. Salinities and water temperatures at the time of capture were roughly equivalent in the 2 river systems, ranging from 15 to $23 \mathrm{ppt}$ and 12 to $22^{\circ} \mathrm{C}$ respectively. Fish for the chemotactic study were held in tanks of flowing seawater at ambient temperature until use (no longer than 2 wk) and were fed Zeigler's Trout Chow daily

Fish for the virulence studies were obtained as described above and were housed at room temperature in 10 gallon ( $38 \mathrm{l}$ ) aquaria (ca 20 fish per tank) containing Instant Ocean seawater (Aquarium Systems Inc., Mentor, $\mathrm{OH}, \mathrm{USA}$ ) prepared so that the specific gravity ranged between 1.020 and 1.023. Every other day fish were fed frozen brine shrimp and ca $30 \%$ of the water in each aquarium was replaced with fresh Instant Ocean. The aquaria were kept in a biological safety hood during all experiments.

Micro-organisms. Two cultures of Legionella pneumophila Serogroup 1, Burlington 1 strain, designated virulent and avirulent, were kindly provided by Dr W. C. Winn (Department of Pathology, University of Vermont College of Medicine, Burlington, VT 05405. USA). The original strain was isolated from a patient with Legionnaire's Disease. Bacterial virulence was confirmed by intraperitoneal inoculation of 10 guinea pigs. Both strains were grown in vitro on buffered charcoal yeast extract (CYE) agar (Lenette et al. 1985). Heavy suspensions were made in $1.0 \mathrm{ml}$ aliquots of freezer broth, prepared by mixing equal volumes of trypticase soy broth (Difco, Detroit, MI, USA) and glycerol, and frozen at $-70^{\circ} \mathrm{C}$. For each experiment requiring bacteria, $1 \mathrm{ml}$ aliquots of these suspensions were thawed and plated on buffered CYE agar and incubated at $35^{\circ} \mathrm{C}$ in a $5 \% \mathrm{CO}_{2}$ atmosphere for $3 \mathrm{~d}$. For the chemotactic studies, cells were harvested and suspensions $\left(5 \times 10^{2}\right.$ cells $\left.\mathrm{mI}^{-1}\right)$ were made in $10 \%$ formalin saline solution to kill the organisms. Cells were washed 3 times in sterile $0.6 \% \mathrm{NaCl}$ and plated on CYE agar to verify nonviability. For virulence studies, each strain was streaked for confluent growth on one buffered CYE plate and incubated at $35^{\circ} \mathrm{C}$ in a $5 \% \mathrm{CO}_{2}$ atmosphere for $72 \mathrm{~h}$ before injection. The organisms from each of these plates were suspended in $10 \mathrm{ml}$ of sterile $0.6 \% \mathrm{NaCl}$. Aliquots $(0.01$ to $3.00 \mathrm{ml}$ ) of these suspensions $\left(2.0\right.$ to $3.6 \times 10^{10}$ bacteria $\left.\mathrm{ml}^{-1}\right)$ were removed for injection and for colony counts.

Isolation of kidney macrophages. Fish were killed by severing the spinal cord adjacent to the skull with a scalpel. The kidneys were aseptically removed and transferred to Minimal Essential Medium (MEM) (GIBCO) supplemented with $0.33 \%$ glucose, $500 \mathrm{U}$ $\mathrm{ml}^{-1}$ penicillin, $0.3 \mathrm{mg} \mathrm{ml}^{-1}$ streptomycin, $0.1 \mathrm{U} \mathrm{ml}^{-1}$ heparin and $10 \%$ fetal calf serum. Kidney tissue was homogenized and clumps of cells were allowed to setthe in a $10 \mathrm{ml}$ plastic test tube. Macrophages were separated from the total cell suspension using a modification of the Percoll density gradient technique of Braun-Nesje et al. (1981) (Weeks et al. 1976). The macrophage fractions were removed from the gradients and the viable cell concentration was determined by trypan blue exclusion. Macrophage identity was based on nonspecific esterase stain, morphological characteristics using light microscopy, and phagocytosis of Escherichia coli as confirmed by electron microscopy (Weeks \& Warinner 1984).

Chemotaxis assay. Chemotaxis assays were performed with normal fish macrophages isolated from 12 to 25 fish per experiment. The chemotactic activity was quantified by a moditication of the Boyden microscopic filter technique (Boyden 1962, Weeks et al. 1986) using a double chamber apparatus (Nuclepore Corp., Bethesda, MD, USA) which was washed in $95 \%$ ethanol, thoroughly rinsed in sterile distilled water and air-dried at $37^{\circ} \mathrm{C}$ before use. The lower chamber contained $0.2 \mathrm{ml}$ of an appropriate suspension of formalinkilled Legionella pneumophila $\left(1 \times 10^{8}\right.$ bacteria $)$ in teleost-buffered saline (TBS) (Forster \& Taggart 1950) adjusted to $0.6 \%$ salinity and containing $10 \% \mathrm{v} / \mathrm{v}$ human serum. Controls contained $0.2 \mathrm{ml}$ of TBS with $10 \%$ human serum in the lower chamber. The upper chamber contained an equal volume of $1 \times 10^{5}$ macrophages suspended in MEM. The 2 chambers were separated by a Nuclepore $13 \mathrm{~mm}$ polycarbonate membrane filter ( $8 \mu \mathrm{m}$ pore size) which allowed the passage of chemotactically-stimulated macrophages from the upper to the lower surface of the filter. Three pairs of chambers were incubated at $15^{\circ} \mathrm{C}$. At 30,60 and $90 \mathrm{~min}$ time periods, pairs of membrane filters were removed, fixed with methanol and stained with Wright's stain. Macrophages were differentially counted on the upper and lower surfaces of the membrane filter. Results were expressed as percent chemotaxis or the ratio of macrophages on the lower surface of the membrane to the total number of macrophages counted (at least 100) $\times 100$. The mean \pm standard error of the mean (SE) of the chemotactic indices at 30,60 and $90 \mathrm{~min}$ was determined for each of the 2 strains, and the differences between the 2 strains were evaluated by a 1 -tailed Student's t-test.

Virulence assay. Fish were injected intraperitoneally with $0.5 \mathrm{ml}$ or $0.4 \mathrm{ml}$ (ca $2 \times 10^{10}$ cells) of either the virulent or the avirulent bacterial suspension. Uninoculated fish or fish inoculated with sterile $0.6 \% \mathrm{NaCl}$ were used as controls. Tanks were checked at least twice daily and any dead fish were removed. The peritoneal cavity of each dead fish was entered aseptically, samples were collected with a cotton swab and cultured on buffered CYE agar containing cefaman- 
dole, polymyxin B and anisomycin (Lenette et al. 1985). Smears of the peritoneal cavity were made, stained with Wright's stain and then stained with Giemsa stain. These smears were examined microscopically for the presence of macrophages.

\section{RESULTS}

Chemotactic experiments utilized 2 chemoattractants for macrophages obtained from Leiostomus xanthurus: one avirulent and one virulent strain of Legionella pneumophila. The results are shown in Table 1. Chemotactic activity increased at each time interval, reaching maximum values within $90 \mathrm{~min}$ for both virulent and avirulent strains. Migration was significantly $(p<0.001)$ greater for avirulent $L$. pneumophila at all time periods. Values at $90 \mathrm{~min}$ were $60.5 \pm$ $2.6 \%$ and $24.3 \pm 1.9 \%$ for avirulent and virulent strains, respectively.

Results of the in vivo mortality experiments using the virulent and avirulent strains of Legionella pneumo-

Table 1 Chemotactic index of Leiostomus xanthurus (spot) macrophages toward 2 strains of Legionella pneumophila. Values are expressed as the ratio of macrophages on the lower surface of the filter of the total number of macrophages counted $\times 100$. Each value represents the mean \pm SE of duplicate chambers from 3 experiments using 12 to 25 fish per experiment. The virulent group differed significantly $(p<0.001)$ from the avirulent group at all time periods. In both groups, chemotactic migration was significantly higher than random migration controls at each time interval $(p<0.001)$

\begin{tabular}{|c|c|c|}
\hline \multirow{2}{*}{ Incubation time } & \multicolumn{2}{|c|}{ Chemotactic index } \\
\hline & Virulent strain & Avirulent strain \\
\hline $30 \mathrm{~min}$ & $10.5 \pm 1.6$ & $25.7 \pm 1.3$ \\
\hline $60 \mathrm{~min}$ & $22.3 \pm 1.9$ & $40.5 \pm 2.2$ \\
\hline $90 \mathrm{~min}$ & $24.3 \pm 1.9$ & $60.5 \pm 2.6$ \\
\hline
\end{tabular}

phila are shown in Table 2. All fish injected with the virulent strain died within $48 \mathrm{~h}$ (11 of 13 within $24 \mathrm{~h}$ ) while 7 of the 12 fish receiving the avirulent strain died within $48 \mathrm{~h}$ (all deaths occurred between 24 and $48 \mathrm{~h}$ ). L. pneumophila was recovered by culture from the peritoneal cavity in $100 \%$ of the fish. The peritoneal smears from the avirulent L. pneumophila-injected fish consistently showed the presence of a large number of macrophages. The smears from the virulent $L$. preumophila-inoculated fish had small numbers of macrophages in some fish and none in others. No control fish died within $48 \mathrm{~h}$ in either experiment.

\section{DISCUSSION}

The observation that Leiostomus xanthurus macrophages are chemotactic to Legionella pneumophila is consistent with our earlier results showing them to be chemotactic toward Escherichia coli (Weeks et al. 1986). The microscopic observation of greater numbers of macrophages present in the peritoneum of fish inoculated with avirulent as opposed to virulent $L$. pneumophila was consistent with the in vitro chemotactic results which showed a much greater chemotactic response to the avirulent strain than to the virulent strain. The relationship of chemotactic activity and virulence cannot be definitely established by the results presented here, but there appears to be a correlation between low chemotactic acitivity and high virulence. It should be emphasized that the virulent and avirulent strains were both derived from the same parent strain, with the avirulent strain being produced by continuous in vitro passage while the virulent strain was passed in guinea pigs. Thus the relationship of the 2 strains was very close and the only apparent difference was in their pathogenic potential.

Guinea pig experimental results (Bollin et al. 1985, Plouffe et al. 1985) have been used to distinguish viru-

Table 2. Leiostomus xanthurus (spot) mortality due to virulent and avirulent Legionella pneumophila

\begin{tabular}{|c|c|c|c|c|c|c|c|}
\hline \multirow{2}{*}{$\begin{array}{l}\text { L. pneumophila } \\
\text { strain type }\end{array}$} & \multirow{2}{*}{$\begin{array}{l}\text { No. of organisms } \\
\text { injected }\left(\times 10^{10}\right)\end{array}$} & \multirow[t]{2}{*}{ No. of fish } & \multicolumn{3}{|c|}{ Time of death (h) } & \multirow{2}{*}{$\begin{array}{l}\text { Total } \\
\text { dead }\end{array}$} & \multirow{2}{*}{$\begin{array}{l}\text { Total living } 48 \text { h } \\
\text { after injection }\end{array}$} \\
\hline & & & 24 & 36 & 48 & & \\
\hline \multicolumn{8}{|l|}{ Expt. I } \\
\hline Virulent & 1.0 & 5 & 4 & 1 & 0 & 5 & 0 \\
\hline Avirulent & 1.5 & 4 & 0 & 2 & 1 & 3 & 1 \\
\hline Control & 0 & 4 & 0 & 0 & 0 & 0 & 4 \\
\hline \multicolumn{8}{|l|}{ Expt. II } \\
\hline Virulent & 1.3 & 4 & 3 & 0 & 1 & 4 & 0 \\
\hline Virulent & 1.0 & 4 & 4 & 0 & 0 & 4 & 0 \\
\hline Avirulent & 1.8 & 4 & 0 & 3 & 0 & 3 & 1 \\
\hline Avirulent & 1.5 & 4 & 0 & 0 & 1 & 1 & 3 \\
\hline Control & 0 & 5 & 0 & 0 & 0 & 0 & 5 \\
\hline
\end{tabular}


lent and avirulent strains of Legionella pneumophila, with a significantly smaller inoculum of the virulent strain consistently killing guinea pigs. It is interesting that the same results were obtained with Leiostomus xanthurus, although the inoculum size needed to kill the latter ( $10^{10}$ bacteria) was several logs higher than that which killed guinea pigs $\left(10^{6}\right.$ to $\left.10^{8}\right)$, indicating that $L$. xanthurus were more resistant to intraperitoneal challenge. The temporal relationship between the 2 models was surprisingly similar with the majority of deaths occurring within $48 \mathrm{~h}$ when an inoculum size of $10^{6}$ for guinea pigs and $10^{10}$ for $L$. xanthurus was used. Identification of the Leiostomus/Legionella virulence model may have value in studying host-parasite relationships and may offer a more economical model than the guinea pig.

Piotein electrophoresis studies performed on these 2 strains have shown differences in protein banding patterns between the strains, and these differences may be related to both the chemotactic and virulence activity of the organisms (Reardon 1985). Further work with different species of fish may or may not show the same association between chemotactic activity and stráin virulence of Legionella pneumophila organisms, but more experiments using the Leiostomus model may aid in identifying factors which can be associated with virulence.

Acknowledgements. We greatly appreciate the valuable tech. nical assistance of Elaine S. Mathews and J. Ernest Warinner. VIMS Contribution No. 1463.

\section{LITERATURE CITED}

Bollin, G. E., Plouffe, J. F., Para, M. F., Prior, R. B. (1985), Difference in virulence of environmental isolates of Legionella pneumophila. J. clin. Microbiol. 21: 674-677
Boyden, S. (1962). The chemotactic effect of maxtures of antibody and antigen on polymorphonuclear leukocytes. J. exp. Med. 15: 453-463

Braun-Nesje, R., Bertheussen, K. Kaplan, G., Seljelid, R. (1981). Salmonid macrophages: separation, in vitro culture and characterization. J. Fish Dis. 4: 141-151

Ellis, A. E. (1977). The leukocytes of fish: a review. J. Fish Biol. 11: $453-491$

Fliermans, C. B., Cherry, W. B., Orrison, L. H., Smith, S. J., Tison, D. L., Pope, D. H. (1981). Ecological distribution of Legionella pneumophila. Appl environ. Microbiol. 41. $9-16$

Forster, R. P., Taggart, J. V \{1950\}. Use of isolated renal tubules for the examination of metabolic processes associated with acitve cellular transport. J. cell. comp. Physiol. 36 (2) : 251-256

Griffin, B. R. (1984). Random and directed migration of trout (Salmo gairdneri) leukocytes: activation by antibody, compiement, and normai serum compunents. Dev. comp. Immunol. 8: 589-597

Lenette, E. H., Balows, A., Hausler, W A., Jr, Shadomy, H. J. (eds.) (1985). Manual of clinical microbiology, 4th edn. American Society for Microbiology, Washington, D. C.

Obenauf, S. D., Smith, S. H. (1985). Chemotaxis of nurse shark leukocytes. Dev. comp. Immunol. 9: 221-230

Plouffe, J. F., Para, M. F., Fuller, K. A. (1985). Serum bactericidal activity against Legionella pneumophila. J. clin. Microbiol. 22: 863-864

Reardon, D. B. (1985). Electrophoretic analysis of soluble proteins from virulent and avirulent Legionella pneumophila. Masters thesis, Virginia Commonwealth University, Richmond

Snyderman, R., Goetzl, E. J. (1981). Molecular and cellular mechanisms of leukocyte chemotaxis. Science 213: $830-837$

Weeks, B. A., Warinner, J. E. (1984). Effects of toxic chemicals on macrophage phagocytosis in two estuarine fishes. Mar environ. Res. 14: 327-335

Weeks, B. A., Warinner, J. E., Mason, P. L., McGinnis, D. S. (1986). Influence of toxic chemicals on the chemotactic response of fish macrophages. J. Fish Biol. 28: 653-658

Wilkinson, P. C. (1974). Chemotaxis and inflammation. Churchill-Livingston, Edinburgh

Responsible Subject Editor: Dr E. B. Shotts; first submitted January 1987; accepted for printing on June 2, 1988 